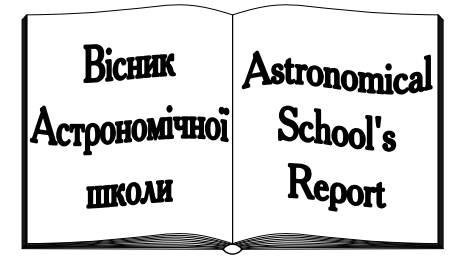

ISSN 1607-2855

UDC 521.528

\title{
On the current estimation of some mechanical and geometrical parameters of the Earth
}

\author{
A.N. Marchenko \\ National University "Lviv Polytechnic”, Lviv, Ukraine
}

The Earth's principal axes and principal moments of inertia, was estimated from the least-squares adjustment of gravitational harmonic coefficients of second degree of recent global Earth gravity models including EIGEN-1S solution and the dynamical ellipticity derived from the precession constant through VLBI. The estimation was made for the time-independent components (at epoch) of the Earth's inertial tensor and the time-dependent components of the tensor of inertia, based on given information on the secular and periodic variations of harmonic coefficients of second degree.

О МЕХАНИЧЕСКИХ И ГЕОМЕТРИЧЕСКИХ ПАРАМЕТРАХ ЗЕМЛИ, Марченко А.Н. - Выполнено совместное уравнивание астрономических и геодезических фундаментальных постоянных с целью установления основных динамических параметров Земли на принятую эпоху. Решение задачи проиллюстрировано на примере определения как временно-независимых (на принятую эпоху), так и временно-зависимых параметров динамической фигуры Земли с учетом вековых и длиннопериодических вариаций внешнего гравитационного поля планеты.

ПРО МЕХАНІЧНІ ТА ГЕОМЕТРИЧНІ ПАРАМЕТРИ ЗЕМЛІ, Марченко О.М. - Розглянуто спільне узгодження астрономічних і геодезичних фундаментальних сталих з метою встановлення основних динамічних параметрів Землі на прийняту епоху. Розв'язування задачі проілюстровано на прикладі визначення як незалежних від часу (на прийняту епоху), так $i$ залежних від часу параметрів динамічної фігуры Землі з врахуванням неперіодичних неприпливних варіачій зовнішнього гравітачійного поля планети.

\section{INTRODUCTION}

Current estimation of the Earth's mechanical and geometrical parameters of common relevance of Astronomy, Geodesy, and Geodynamics represents traditionally one of the basic objectives of different Commissions and Study Groups of the IAG (see, for instance, Groten 2000). Consistent sets of the Earth's mechanical and geometrical parameters associated with the degree 2 coefficients $\bar{C}_{2 m}, \bar{S}_{2 m}$ of the spherical harmonic expansion of the geopotential and the Earth's inertial tensor was obtained recently by (Marchenko and Schwintzer, 2001; Marchenko and Shwintzer, 2002). The Earth's principal axes $(\bar{A}, \bar{B}, \bar{C})$, principal moments of inertia $(A, B, C)$, and other fundamental constants were estimated in the mentioned papers from satellitederived gravitational harmonic coefficients of second degree in global Earth gravity models and from the dynamical ellipticity resulting from the precession constant observed through VLBI. This paper will focus on further current determination of the Earth's fundamental parameters, involving the recent gravity field model EIGEN-1S in this solution. 
Table 1. Determinations of the dynamical ellipticity $H_{D}$

\begin{tabular}{|lccl|}
\hline \multicolumn{1}{|c}{ Reference } & $\begin{array}{c}\text { Precession constant } \\
p_{A}\left[{ }^{\prime \prime} / \mathrm{yr}\right], \mathrm{J} 2000\end{array}$ & $\begin{array}{c}H_{D} \\
\text { Epoch }=2000\end{array}$ & Epoch $=1997$ \\
\hline Williams, 1994 & 50.287700 & 0.0032737634 & 0.00327376364 \\
Souchay and Kinoshita, 1996 & 50.287700 & 0.0032737548 & 0.00327375504 \\
Hartmann et al., 1997, 1999 & 50.288200 & 0.003273792489 & \\
& $(50.287700)^{\mathrm{a}}$ & $(0.0032737600)^{\mathrm{a}}$ & 0.00327376024 \\
Bretagnon et al., 1998 & 50.287700 & 0.003273766818 & 0.00327376705 \\
& & \pm 0.000000000023 & \\
Roosbeek and Dehant, 1998 & 50.287700 & 0.0032737674 & 0.00327376764 \\
Mathews, 2000 & 50.288018 & 0.0032737875 & \\
& \pm 0.000008 & \pm 0.0000000005 & 0.00327376708 \\
\hline
\end{tabular}

${ }^{\mathrm{a}}$ Transformed to common value of precession constant

\section{ADJUSTMENT OF ASTRONOMICAL AND GEODETIC PARAMETERS}

The fully normalized harmonic coefficients $\bar{C}_{2 m}, \bar{S}_{2 m}$ are selected from the following gravity field satellite solutions: two models resulting from a combination of satellite tracking, altimetry and gravimetry data, JGM3 (Tapley et al., 1996) and EGM96 (Lemoin et al., 1998), and two satellite-only models, GRIM5-S1 (Biancale et al., 2000) and EIGEN-1S (Reigber et al., 2001). EIGEN-1S is a satellite-only gravity field model including 88 days of CHAMP data, which contains fully normalized spherical harmonic coefficients complete to degree/order 100 with higher terms up to degree 119. Various time variable coefficients in these models are referred to different epochs with a spacing of 11 years. The following transformations were made beforehand. 1) Prediction of the JGM-3 and EGM96 $\bar{C}_{2 m}(t), \bar{S}_{2 m}(t)$ to the chosen epoch 1997. 2) Scaling of these coefficients to common values $G M$ and $a .3$ ) Reduction of $\bar{C}_{20}$ to an adopted tide system. For the transformation from $\bar{C}_{20}^{Z}$, in the zerofrequency tide system, to $\bar{C}_{20}^{f}$, in the tide-free system, the standard reduction $\bar{C}_{20}^{f}=\bar{C}_{20}^{Z}-\delta_{Z}$ $\left(\delta_{Z}=3.1108 \cdot 10^{-8} \cdot 0.3 / \sqrt{5}\right)$ was applied.

The best fitting principal moments of inertia and second-degree harmonic coefficients in the principal axes system are found from the least-squares adjustment, involving these four global gravity field models and six different values for the dynamical ellipticity (Williams, 1994; Souchay and Kinoshita, 1996; Hartmann et al. 1997; Bretagnon et al. 1998; Roosbeek and Dehant, 1998; Mathews, 2000) all transformed to common precession constant (see Table 1). From the values of $H_{D}$ given in Table 1 the estimations of Hartmann et al. (1999) and Mathews (2000) differ in the adopted precession constant. To transform the associated quantities to the common $p_{A}=50.2877 \mathrm{n} / \mathrm{yr}$ the differential relationship of Souchay and Kinoshita (1996) $\delta H_{D}=6.4947 \cdot 10^{-7} \delta p_{A}$ (obtained according to the rigid Earth's precession-nutation theory) was used to compute the values $H_{D}$ given in brackets in Table 1.

Note also that the first 5 values of $H_{D}$ were derived in the frame of the rigid Earth's precession-nutation theory. According to Mathews (2001, Private communication) after removing the non-rigidity contribution from the new "non-rigid" value $p_{A}=50.287923$ " /yr, which are corresponded to the MHB2000 theory, "the reduced value for $H_{D}$ becomes 0.0032737667 , which differs by only 1 in the last digit".

To transform the values $H_{D}$ from J2000 to 1997, an additional correction $\delta h$ was applied. In view of Yoder et al. (1983) the non-tidal variation $\delta C$ in the moment of inertia $C$ as a function of $\dot{\bar{C}}_{20}$ only (secular variation in the second-degree zonal coefficient), the equation (3) for $H_{D}$, and the treatment $\delta A=\delta B=-\delta C / 2$ "as zonal forces do not change the revolution shape of the body" (Melchior, 1978), we come to the condition for the trace $\operatorname{TrI}=$ const of the Earth's tensor of inertia I (Rochester and Smylie, 1974) and by this get immediately the secular 
variation in $H_{D}$ :

Numerically we get

$$
\dot{H}_{D}=\frac{\dot{\bar{C}}_{20}}{\bar{C}_{20}} H_{D}\left(1-\frac{2}{3} H_{D}\right) .
$$

$$
\dot{H}_{D}=(-7.864 \pm 0.270) \cdot 10^{-11} \mathrm{yr}^{-1},
$$

using the observed secular rate $\dot{\bar{C}}_{20}=(1.16553188 \pm 0.04) \cdot 10^{-11} \mathrm{yr}^{-1}$ of change in the second-degree zonal coefficient, taken from the GRIM5-S1CH1 model (GFZ/GRGS internal solution, 2001) that gives $\delta h=2.36 \cdot 10^{-10}$ for the reduction of the $H_{D}$ values from the year 2000 to 1997. So that $H_{D}$ used in the following adjustment are the reduced ones (see Table 1).

With the normalized 2nd degree harmonic coefficients $\bar{A}_{20}$ and $\bar{A}_{22}$ given in the principal axes

$$
\left.\begin{array}{l}
H_{D}=(2 C-A-B) / 2 C \\
\bar{A}_{20}=(A+B-2 C) / 2 \sqrt{5} \\
\bar{A}_{22}=3(B-A) / 2 \sqrt{15}
\end{array}\right\},
$$

the computation of

$$
C=-\sqrt{5} \cdot \bar{A}_{20} / H_{D}
$$

$A, B$, the sum

$$
A+B=\sqrt{5} \cdot \bar{A}_{20}\left(2-\frac{2}{H_{D}}\right)
$$

and the trace of the Earth's inertial tensor

$$
\operatorname{Tr} \mathbf{I}=A+B+C=\sqrt{5} \cdot \bar{A}_{20}\left(2-3 / H_{D}\right)=3 I_{m},
$$

are straightforward. So that we get a direct dependence of $A, B, C$, TrI, and the mean moment $I_{m}$ of inertia on the adopted treatment of the permanent tide in the $\bar{C}_{20} \approx \bar{A}_{20}$ coefficient. Only the difference $B-A=2 \sqrt{15} \cdot \bar{A}_{22} / 3$ is dependent slightly of a permanent tide system. The zero-frequency tide system approximates better the real figure of the Earth. It is assumed that the $H_{D}$ values also are related to this system, although this problem is not discussed in the precession - nutation literature.

The Earth's principal moments of inertia $A, B, C$ are determined from a least-squares adjustment of the astronomical and geodetic parameters, based on the solution of the linearized system of equations (3). As observations are taken the 6 values of $H_{D}$ from Table 1 at epoch 1997 and the 4 sets of harmonic coefficients $\bar{A}_{20}, \bar{A}_{22}$ in the principal axes system (all chosen at epoch 1997), computed according to the closed expressions given in (Marchenko and Abrikosov, 2001) from the coefficients $\bar{C}_{2 m}, \bar{S}_{2 m}$ of the JGM-3, EGM96, GRIM5S1, and EIGEN-1S gravity field models. The adjusted in this manner final value of the dynamical ellipticity is

$$
H_{D}=0.003273763447 \pm 0.0000000035 \quad(\text { epoch }=1997) \text {. }
$$

Note that derived in the same way value of the dynamical ellipticity at epoch 1997 is $H_{D}=0.003273763447 \pm 0.0000000032$ (Marchenko and Shwintzer, 2002), where GRIM5-S1CH1 solution was used instead of the EIGEN-1S gravity model.

\section{ADJUSTMENT OF GEODETIC PARAMETERS}

Let us express the vector $\mathbf{g}$ of the harmonic coefficients $\bar{C}_{2 m}$ and $\bar{S}_{2 m}$, adopted in the frame $X Y Z$, via the vector $\mathbf{g}_{Z^{\prime}}=\left[\bar{A}_{20} ; \bar{A}_{21} ; \bar{B}_{21} ; \bar{A}_{22} ; \bar{B}_{22}\right]^{\mathrm{T}}$ given in the close to $X Y Z$ coordinate system $X^{\prime} Y^{\prime} Z^{\prime}$ whose axis $Z^{\prime}$ has a 
Table 2. Results of a simultaneous adjustment of the $\bar{C}_{2 m}, \bar{S}_{2 m}$ parameters (zero-frequency-tide system; $G M=398600.4415 \mathrm{~km}^{3} / \mathrm{s}^{2} ; a=6378136.49 \mathrm{~m} ; \bar{x}_{p}=0.040^{\prime \prime}, \bar{y}_{p}=0.340^{\prime \prime}$;

$H_{D}=0.003273763447 \pm 0.0000000035 ; \dot{H}_{D}=(-7.864 \pm 0.270) \cdot 10^{-11} \mathrm{yr}^{-1} ;$ epoch: 1997)

\begin{tabular}{|c|c|}
\hline Parameter & JGM-3, EGM96, GRIM5-S1, EIGEN-1S \\
\hline $\bar{C}_{20} \cdot 10^{6}$ & $-0.000165 \pm 0.000015$ \\
$\bar{C}_{21} \cdot 10^{6}$ & $0.001379 \pm 0.000014$ \\
$\bar{S}_{21} \cdot 10^{6}$ & $2.439289 \pm 0.000010$ \\
$\bar{C}_{22} \cdot 10^{6}$ & $-1.400263 \pm 0.000010$ \\
$\bar{S}_{22} \cdot 10^{6}$ & $1086.266674 \pm 0.000022$ \\
\hline Derived & $1079.004505 \pm 0.000022$ \\
$(C-A) \cdot 10^{6}$ & $7.262169 \pm 0.000025$ \\
$(C-B) \cdot 10^{6}$ & $0.32961435 \pm 0.00000035$ \\
$(B-A) \cdot 10^{6}$ & $0.32962161 \pm 0.00000035$ \\
$A$ & $0.33070062 \pm 0.00000035$ \\
$B$ & $0.32997886 \pm 0.00000035$ \\
$C$ & $(3273.5362 \pm 0.0035) \cdot 10^{-6}$ \\
$I_{m}=(A+B+C) / 3$ & $(3295.4960 \pm 0.0035) \cdot 10^{-6}$ \\
$\alpha=(C-B) / A$ & $(21.9600 \pm 0.00008) \cdot 10^{-6}$ \\
$\beta=(C-A) / B$ & $298.256490 \pm 0.000008$ \\
$\gamma=(B-A) / C$ & $91437.5 \pm 0.3$ \\
\hline $1 / f$ & \\
\hline
\end{tabular}

small displacement from the axis $Z$ of the Earth's pole coordinates magnitude. By applying the same approach as discussed in (Marchenko and Schwintzer, 2001) we will use the relationship $\mathbf{g}=\mathbf{P} \cdot \mathbf{g}_{Z}{ }^{\prime}$ with the matrix $\mathbf{P}$ written in the following form

$$
\mathbf{P}=\left(\begin{array}{ccccc}
\frac{2-s_{1}}{2} & -\sqrt{3} x_{p} & \sqrt{3} y_{p} & \frac{\sqrt{3} s_{2}}{2} & -\sqrt{3} x_{p} y_{p} \\
\sqrt{3} x_{p} & 1-x_{p}^{2} & x_{p} y_{p} & -x_{p} & y_{p} \\
-\sqrt{3} \bar{y}_{p} & x_{p} y_{p} & 1-y_{p}^{2} & -y_{p} & -x_{p} \\
\frac{s_{2}}{\sqrt{3}} & x_{p} & y_{p} & 1 & 0 \\
-\frac{2 x_{p} y_{p}}{\sqrt{3}} & -y_{p} & x_{p} & 0 & 1
\end{array}\right),
$$

where $s_{1}=x_{p}^{2}+y_{p}^{2}, s_{2}=x_{p}^{2}-y_{p}^{2}$. Since the determinant $\operatorname{Det}(\mathbf{P}) \neq 0$, there is the inverse linear transformation

$$
\mathbf{g}_{Z^{\prime}}=\mathbf{P}^{-1} \cdot \mathbf{g}
$$

where the matrix $\mathbf{P}^{-1}$ was derived also in an analytical way. By this the expression (9) allows to compute all coefficients $\bar{A}_{2 m}$ and $\bar{B}_{2 m}$ related to the axis $Z^{\prime}$. According to (9) then $\bar{A}_{21}$ and $\bar{B}_{21}$ read 
Table 3. Spherical coordinates of the principal axes and their uncertainties $(e p o c h=1997)$

\begin{tabular}{|lcccccc|}
\hline $\begin{array}{l}\text { Gravity field } \\
\text { model }\end{array}$ & $\begin{array}{c}\varphi(\bar{A})) \\
\text { [degree] }\end{array}$ & $\begin{array}{c}\lambda(\bar{A}) \\
\text { [degree] }\end{array}$ & $\begin{array}{c}\varphi(\bar{B})) \\
\text { [degree] }\end{array}$ & $\begin{array}{c}\lambda(\bar{B})) \\
\text { [degree] }\end{array}$ & $\begin{array}{c}\varphi(\bar{C}) \\
\text { [degree] }\end{array}$ & $\begin{array}{c}\lambda(\bar{C}) \\
\text { [degree] }\end{array}$ \\
\hline JGM-3 & -0.000033 & 345.0709 & 0.000076 & 75.0709 & 89.999917 & 278.75 \\
& \pm 0.000003 & \pm 0.0004 & \pm 0.000003 & \pm 0.0004 & \pm 0.000003 & \pm 1.92 \\
EGM96 & -0.000039 & 345.0712 & 0.000087 & 75.0712 & 89.999905 & 279.05 \\
& \pm 0.000003 & \pm 0.0006 & \pm 0.000003 & \pm 0.0006 & \pm 0.000003 & \pm 1.67 \\
GRIM5-S1 & -0.000034 & 345.0711 & 0.000085 & 75.0711 & 89.999908 & 276.88 \\
& \pm 0.000002 & \pm 0.0001 & \pm 0.000002 & \pm 0.0001 & \pm 0.000002 & \pm 1.33 \\
EIGEN-1S & -0.0000353 & 345.07110 & 0.0000894 & 75.07110 & 89.9999040 & 276.60 \\
& \pm 0.0000006 & \pm 0.00005 & \pm 0.0000005 & \pm 0.00005 & \pm 0.0000005 & \pm 0.33 \\
Adjusted $\bar{C}_{2 m}$, & -0.0000351 & 345.07111 & 0.0000884 & 75.07111 & 89.9999049 & 276.71 \\
$\bar{S}_{2 m}$ (Table 2) & \pm 0.0000010 & \pm 0.00010 & \pm 0.0000009 & \pm 0.00010 & \pm 0.0000009 & \pm 0.62 \\
\hline
\end{tabular}

$$
\begin{gathered}
\bar{A}_{21}=-\frac{2 \sqrt{3} \bar{x}_{p} p_{3}}{3 p_{2} p_{1}^{2}} \bar{C}_{20}+\frac{1-p_{5}}{p_{1}^{2}} \bar{C}_{21}+\frac{2 \bar{x}_{p} \bar{y}_{p}}{p_{1}^{2}} \bar{S}_{21}+\frac{2 \bar{x}_{p} p_{4}}{p_{1} p_{2}} \bar{C}_{22}+\frac{\bar{y}_{p}\left(p_{3}-2\right)}{p_{1} p_{2}} \bar{S}_{22}, \\
\bar{B}_{21}=\frac{2 \sqrt{3} \bar{y}_{p} p_{3}}{3 p_{2} p_{1}^{2}} \bar{C}_{20}+\frac{2 \bar{x}_{p} \bar{y}_{p}}{p_{1}^{2}} \bar{C}_{21}+\frac{1+p_{5}}{p_{1}^{2}} \bar{S}_{21}+\frac{2 \bar{y}_{p}\left(\bar{x}_{p}^{2}+1\right)}{p_{1} p_{2}} \bar{C}_{22}+\frac{\bar{x}_{p}\left(p_{5}+2\right)}{p_{1} p_{2}} \bar{S}_{22},
\end{gathered}
$$

where $p_{1}=s_{1}+1, p_{2}=s_{1}+2, p_{3}=s_{1}+3$ and the coefficients $\bar{A}_{21}$ and $\bar{B}_{21}$ must be zero at a reference epoch by definition, if the axis $Z^{\prime}$ and the figure axis $\bar{C}$ are coinciding. The obtained differences from zero lead to the conclusion that each of the considered gravity models is referred to its own reference system.

To avoid these differences only one set of the harmonic coefficients $\bar{C}_{2 m}$ and $\bar{S}_{2 m}$ (at epoch 1997) was determine from the least squares adjustment as in the preceding solution (Marchenko and Schwintzer, 2001). For 4 adopted gravity models we compute the harmonic coefficients $\bar{A}_{2 m}^{(j)}, \bar{B}_{2 m}^{(j)}(j=1,2, \ldots 4)$. So that the vector $\mathbf{g}_{Z^{\prime}}$ consists of 5 coefficients $\bar{A}_{2 m}^{(j)}, \bar{B}_{2 m}^{(j)}$ for each $j$. Further we consider (9) as the linear observation equation system with respect to the 5 unknowns $\bar{C}_{2 m}, \bar{S}_{2 m}$ of the vector $\mathbf{g}$. The inverse matrix $\mathbf{P}^{-1}$ of this system depends only on the mean pole coordinates selected at epoch 1997. Two additional conditions are added to the equation system (9) according to (10) with zero left-hand sides.

Taking for all 4 gravity models the harmonic coefficients $\bar{A}_{2 m}^{(j)}$ and $\bar{B}_{2 m}^{(j)}$ in the $X^{\prime} Y^{\prime} Z^{\prime}$ frame as observations, we get in this way the adjusted $\bar{C}_{2 m}, \bar{S}_{2 m}$ coefficients at epoch 1997, given in Table 2. These harmonic coefficients restore exactly the adopted mean pole coordinates $x_{p}=0.040^{\prime \prime}, y_{p}=0.340^{\prime \prime}$. Table 2 contains also the geometrical polar $f$ and equatorial $f_{e}$ flattening at epoch 1997 and other derived parameters based on the adjusted before dynamical ellipticity (7). The orientation of the principal axes $\bar{A}, \bar{B}$, and $\bar{C}$ are computed for each of the four individual gravity field models and for the adjusted set of second degree coefficients (Table 3).

\section{CONCLUSIONS}

Table 4 summarizes the geodetic and astronomical fundamental Earth parameters given at two different epochs and demonstrates their temporal changes caused by $\bar{C}_{21}(t), \bar{S}_{21}(t)$ (or the long-periodic model (Marchenko and Schwintzer, 2001) for the mean pole coordinates $\left.\bar{x}_{p}(t), \bar{y}_{p}(t)\right)$ and the secular variation $\dot{\bar{C}}_{20}$, taken from the GRIM5-S1CH1 gravity field model. The condition $\delta A=\delta B=-\delta C / 2$ to conserve the trace 
Table 4. Consistent system of fundamental geodetic and astronomical parameters and their temporal differences over 38 years versus uncertainty (zero-frequency tide system; $G M=398600.4415 \mathrm{~km}^{3} / \mathrm{s}^{2} ; \mathrm{a}=6378136.49 \mathrm{~m}$; $\bar{C}_{22}(t)=$ const and $\bar{S}_{22}(t)=$ const were adopted according to Table 2$)$

\begin{tabular}{|cllcc|}
\hline Parameter: $P(t)$ & $\begin{array}{c}P\left(t_{1}\right) \\
\text { Epoch: } t_{1}=1962\end{array}$ & $\begin{array}{c}P\left(t_{2}\right) \\
\text { Epoch: } t_{2}=2000\end{array}$ & $\begin{array}{c}\text { Difference: } \\
P\left(t_{2}\right)-P\left(t_{1}\right)\end{array}$ & $\begin{array}{c}\text { Standard dev. } \sigma \\
\text { for } P \text { at epoch }\end{array}$ \\
\hline Satellite Geodesy only & & & & $0.8 \cdot 10^{-11}$ \\
\hline $\bar{C}_{20} \cdot 10^{6}$ & -484.169763 & -484.169320 & $+4.43 \cdot 10^{-10}$ & $1.5 \cdot 10^{-11}$ \\
$\bar{C}_{21} \cdot 10^{6}$ & 0.000020 & -0.000175 & $-1.95 \cdot 10^{-10}$ & $1.4 \cdot 10^{-11}$ \\
$\bar{S}_{21} \cdot 10^{6}$ & 0.000741 & 0.001436 & $+6.95 \cdot 10^{-10}$ & $2.2 \cdot 10^{-11}$ \\
$(C-A) \cdot 10^{6}$ & 1086.267586 & 1086.266596 & $-0.990 \cdot 10^{-9}$ & $2.2 \cdot 10^{-11}$ \\
$(C-B) \cdot 10^{6}$ & 1079.005417 & 1079.004427 & $-0.990 \cdot 10^{-9}$ & $2.5 \cdot 10^{-11}$ \\
$(B-A) \cdot 10^{6}$ & 7.262169 & 7.262169 & $-1.6 \cdot 10^{-15}$ & $0.8 \cdot 10^{-5}$ \\
$1 / f$ & 298.256369 & 298.256500 & $+1.31 \cdot 10^{-4}$ & 0.3 \\
$1 / f_{\mathrm{e}}$ & 91437.5 & 91437.5 & $+1.8 \cdot 10^{-5}$ & $3.5 \cdot 10^{-9}$ \\
\hline Astronomy + Geodesy & & & $-3.0 \cdot 10^{-9}$ & $3.5 \cdot 10^{-7}$ \\
\hline$H_{D}$ & 0.0032737662 & 0.0032737632 & $+3.3 \cdot 10^{-10}$ & $3.5 \cdot 10^{-7}$ \\
$B$ & 0.32961434930 & 0.32961434963 & $+3.3 \cdot 10^{-10}$ & $3.5 \cdot 10^{-7}$ \\
$C$ & 0.32962161147 & 0.32962161180 & $-6.6 \cdot 10^{-10}$ & $3.5 \cdot 10^{-7}$ \\
$I_{m}$ & 0.33070061689 & 0.33070061623 & $+0.1 \cdot 10^{-12}$ & $3.5 \cdot 10^{-9}$ \\
$(C-B) / A$ & 0.32997885922 & 0.32997885922 & $-3.0 \cdot 10^{-9}$ & $3.5 \cdot 10^{-9}$ \\
$(C-A) / B$ & $3273.5390 \cdot 10^{-6}$ & $3273.5360 \cdot 10^{-6}$ & $-3.0 \cdot 10^{-9}$ & $0.8 \cdot 10^{-10}$ \\
\hline$B-A) / C$ & $3295.4987 \cdot 10^{-6}$ & $3295.4957 \cdot 10^{-6}$ & $+4.0 \cdot 10^{-14}$ & \\
\hline
\end{tabular}

of the Earth's inertial tensor when changing $\bar{C}_{20}$ was applied again. Residual long-periodic fluctuations in TraceI (of the $10^{-14} \mathrm{yr}^{-1}$ order) are explained now by the time-varying $\bar{C}_{21}, \bar{S}_{21}$ coefficients adopted in the XYZ frame and require an additional non-linear reduction in $H_{D}=H_{D}(t)$ computed in the principal axes ABC system.

All these values represent the consistent system of parameters, which were found by a simultaneous adjustment of the most recent geodetic and astronomical observations. Nevertheless, the comparison of their time evolution with the standard deviations $\sigma$ gives significant results only for the first set of parameters coming from satellite geodesy (Table 4). Second subset requires a more careful study of parameters' transformation into $A B C$ system in view of some additional effects induced by the $\bar{C}_{20}, \bar{C}_{21}, \bar{S}_{21}$ changes and the adopted reference frame. Despite of small differences with respect to parameters from previous solutions we come again to obtained in (Marchenko and Schwintzer, 2002) qualitative result: "Differences in the principal moments of inertia turn out to change significantly over the time interval from 1962 to 2000, whereas changes in the absolute values cannot be reliably resolved due to the uncertainty in the dynamic ellipticity".

1.Biancale R., Balmino G., Lemoine J.-M., Marty J.-C., Moynot B., Barlier F., Exertier P., Laurain O., Gegout P., Schwintzer P., Reigber Ch., Bode A., König R., Massmann F.-H., Raimondo J.C., Schmidt R., Zhu S.Y. A New Global Earth's Gravity Field Model from Satellite Orbit Perturbations: GRIM5-S1 // Geophysical Research Letters. - 2000. - 27. P.3611-3614.

2.Bretagnon P., Francou G., Rocher P., Simon J.L. SMART97: A new solution for the rotation of the rigid Earth // As.Ap. 1998. - 329. - P.329-338.

3.Dehant V., Capitaine N. On the luni-solar precession, the Tilt-Over-Mode, and the Oppolzer terms // Cel.Mech.Dyn.Astron. - 1997. - 65. - P.439-458.

4.Groten E. Parameters of Common Relevance of Astronomy, Geodesy, and Geodynamics // Journal of Geodesy. - 2000. 74. - P.134-140.

5.Hartmann T., Soffel M., Ron C. The geophysical approach towards the nutation of a rigid Earth, Supplement Series // As.Ap.- 
1999. - 134. - P.271-286.

6.Lemoine F.G., Kenyon S.C., Factor J.K., Trimmer R.G., Pavlis N.K., Chinn D.S., Cox C.M., Klosko S.M., Luthcke S.B., Torrence M.H., Wang Y.M., Williamson R.G., Pavlis E.C., Rapp R.H., Olson T.R. The Development of the Joint NASA GSFC and the National IMagery and Mapping Agency (NIMA) Geopotential Model EGM96. NASA Technical Paper NASA/TP-1998-206861, Goddard Space Flight Center, Greenbelt, USA.

7.Mathews P.M. Improved models for precession and nutation // In: Proc Of IAU Colloquium 180 "Towards Models and Constants for Sub-Microarcsecond Astrometry", Naval Observatory, Washington, 27-30 March 2000. - P.212-222.

8.Marchenko A.N., Abrikosov O.A. Evolution of the Earth's principal axes and moments of inertia: The canonical form of solution // Journal of Geodesy, 2001. - 74. - P.655-669.

9.Marchenko A.N., Schwintzer P. Principal axes and principal moments of inertia from recent satellite gravity field solutions. In: J.Adam, K.-P.Schwarz (Eds.) "Vistas for Geodesy in the New Millennium" // IAG Symposia, vol. 125, IAG 2001 Scientific Assembly, Budapest, Hungary, September 2-7, 2001. Springer. - P.138-143.

10. Marchenko A.N., Schwintzer P. Estimation of the Earth's tensor of inertia from recent global gravity field solutions // Journal of Geodesy (in press), 2002.

11. Melchior P. The tides of the planet Earth. - Pergamon, 1978.

12. Reigber Ch., Balmino G., Schwintzer P., Biancale R.., Bode A., Lemoine J.-M., Koenig R., Loyer S., Neumayer H., Marty J.-C., Barthelmes F., Perosanz F., Zhu S. Y. A high quality global gravity field model from CHAMP GPS tracking data and Accelerometry // Geophysical Research Letters, accepted May 2002.

13. Rochester M.G., Smylie D.E. On changes in the trace of the Earth's inertial tensor // Journal of Geophysical Research. 1974. - 79 (32). - P.4948-4951.

14. Roosbeek F., Dehant V. RDAN97: An analytical development of rigid Earth nutation series using the torque approach // Cel. Mech. and Dyn. Astron. - 1998. - 70. - P.215-253.

15. Souchay J., Kinoshita H. Corrections and new developments in rigid Earth nutation theory: I. Luni-solar influence including indirect planetary effects // As.Ap. - 1996. - 312. - P.1017-1030.

16. Tapley B.D., Watkins M.M., Ries J.C., Davis G.W., Eanes R.J., Poole S.R., Rim H.J., Schutz B.E., Shum C.K., Nerem R.S., Lerch F.J., Marshall J.A., Klosko S.M., Pavlis N.K., Williamson R.G. The Joint Gravity Model 3 // Journal of Geophysical Research. - 1996. - 101, B12. - P.28029-28049.

17. Williams J.G. Contributions to the Earth's obliquity rate, precession and nutation // Astron. J. - 1994. - 108. - P.711-724.

18. Yoder C.F., Williams J.G., Dickey J.O., Schutz B.E., Eanes R.J., and Tapley B.D. Secular variation of earth's gravitational harmonic J2 coefficient from Lageos and nontidal acceleration of earth rotation // Nature. - 1983. - 303 - P.757-762.

Received 12.10.2001 